\title{
THE TRAINING QUALITY IN HIGHER MEDICAL SCHOOLS INFLUENCED BY THE STUDENTS
}

\author{
S. Kyuchukova* \\ Department of Health Care, Medical Faculty, Trakia University, Stara Zagora, Bulgaria
}

\begin{abstract}
PURPOSE: Talking and writing about the training service quality is a delicate topic, especially in the field of Higher education, which prepares personnel for medical practice. A number of factors and conventions influence the training quality of these students. They are major, important and determining component in the process.
\end{abstract}

METHODS: Target: To indicate new objective and subjective factors affecting directly the training process in Higher Medical University (HMU), and to take into account the degree of students' influence on it;

Tasks: To indicate new factors affecting the training process in HMS; to report mathematically and statistically the degree of students' influence on the academic and practical activity; to prepare questionnaires and to process them statistically; to formulate conclusions.

Contingent: 176 medical students and 23 academic tutors from the Faculty of Medicine, Trakia

University, Stara Zagora, Bulgaria.

CONCLUSION\& After completing the tasks, the following conclusions were made:

Students - respondents: $87 \%$ like their university; $61 \%$ find the classroom activities interesting; $2 / 3$ of them do not know the internal rules of their university and faculty.

Teachers - respondents: $97 \%$ indicate the poor general preparation as a stopper; $59 \%$ find the students' self-assessment unrealistic and define it as an obstacle to good coursework.

Key words: Quality; training; students; influence.

\section{INTRODUCTION}

Talking and writing about the quality of educational services is a delicate topic. It should be considered a synchronous process at different levels in the education system. On the one hand, as it's a dynamic characteristic and on the other hand as a guided process (1). The latter is a response and a result of world and European policies, declarations, agreements related to education in general. Some of them are listed below as prerequisites for conducting this study.

And the dynamically changing educational environment can be considered a sum of onestage sections of the process.

\footnotetext{
*Correspondence to: Silviya Georgieva Kyuchukova, Department of Health Care - Trakia University, Stara Zagora 6000, 9 Armeiska Str.,Bulgaria, +359898636514; silviya.kyuchukova@trakia-uni.bg
}

Not everyone touches the quality of a particular area or service, but all of us have been affected by the quality of medical care at least once in our lives. It is immanently related to the quality of medical education and training. Reviewing the problems of quality medical education, Z. Atanasova points out that "it should be based on the requirements of professional competencies and standards for providing effective and quality health care," (2), and M. Nikolova appeals to be clarified the fact that "There is growing necessity to cultivate students' clinical decision-making skills and change their thinking to improve care..."(3).

Professional medical education has been criticized and widely discussed because everyone has an opinion about it, based on their own experience. Every living person has used the services of the health care system and 
has his own point of view for the preparedness of medical experts. As Kr. Miteva emphasizes in her work, "The growing requirements for the quality of patient care require high quality training of nurses and midwives ..." (4). Competence and quality are closely related characteristics of the same training process at HMU. A number of factors and conventions affect the quality of education of these students. They themselves are a major, important and defining component in the dynamic process of their training.

In response to:

$\square$ the EU's strategic goal of using knowledge as a basis for making the European economics the most dynamic and competitive in the world;

The Lisbon Strategy (2007 / C 300/01), focusing on the quality and effectiveness of education (5-6);

The Dakar Framework for Action, adopted by the World Education Forum on 26-28 April 2000 , defining education as a process based on practice and lifelong experience(5-7);

$\square$ The signing of the Bologna Declaration on Development and Modernization of Higher Education, 19 June 1999(5-8);

$\square$ The decision of the $72^{\text {nd }}$ World Health Assembly to designate 2020 as the World Year of the Nurse and Midwife (9),

the goal of the present study was formed.

\section{MATERIALS AND METHODS}

Target: To indicate new objective and subjective factors affecting directly the training process in Higher Medical University (HMU), and to take into account the degree of students' influence on it.
Tasks: To indicate new factors affecting the training process in HMS; to report mathematically and statistically the degree of students' influence on the academic and practical activity; to prepare questionnaires and to process them statistically; to formulate conclusions.

Methods and means: questionnaire; interview; mathematical and statistical processing through IBM SPSS version 20.

Contingent: 176 medical students and 23 academic tutors from the Medical facultaty, the Trakia University - Stara Zagora, Bulgaria. Time interval: Academic year 2018/2019.

\section{RESULTS AND DISCUSSION}

The regulations for the internal order of each HMU are prepared in full synchrony with the laws and by-laws in the Republic of Bulgaria, which concern Higher education, norms of work and rest, trade union agreements, etc. This regulation has individual features for each university, which must be known by the students. It must show them and impose responsibility in them that there are legally justified rules and norms, which regulate and guarantee the strict conduct of the learning process. This is expected to be in the interest of all parties involved in training: teachers, students, administration, supporting staff. Equality and objectivity are guaranteed to all who are affected by its action or inaction. In this regard, all respondents were asked: Are you aware of procedure rules of the university, where you study / work? See Figure 1.

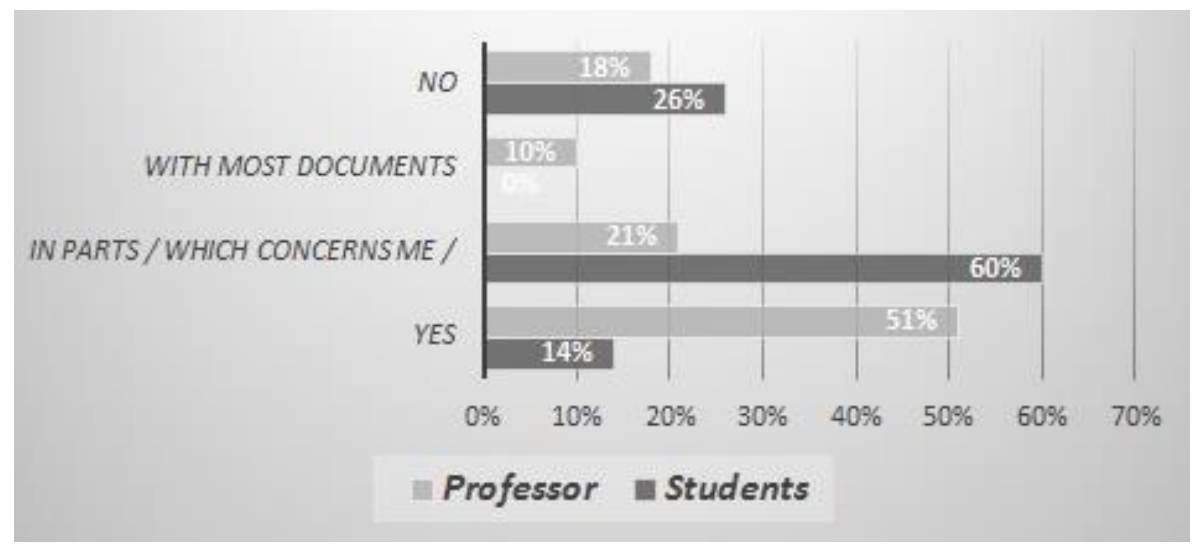

Figure 1. Knowledge of internal regulations

Students know the rules in the part that regulates attendance and assessment $-74 \%$ and the other $26 \%$ are not familiar with it, i.e. we can assume that a quarter of the students are 
strict in their behavior and rely on the correctness of all participants in the learning process and do not find it necessary to know the procedure rules. It is interesting the fact from the study that $18 \%$ of the surveyed teachers do not know the internal rules, and $31 \%$ know them only particularly, but more than half - 51\% firmly say "Yes".
Accepting the Dakar Framework for Action as a basic and defining education as a process, based on practice and lifelong experience, the students involved in the study were asked: Do you learn something new at university that will be useful in your life? (Figure 2)

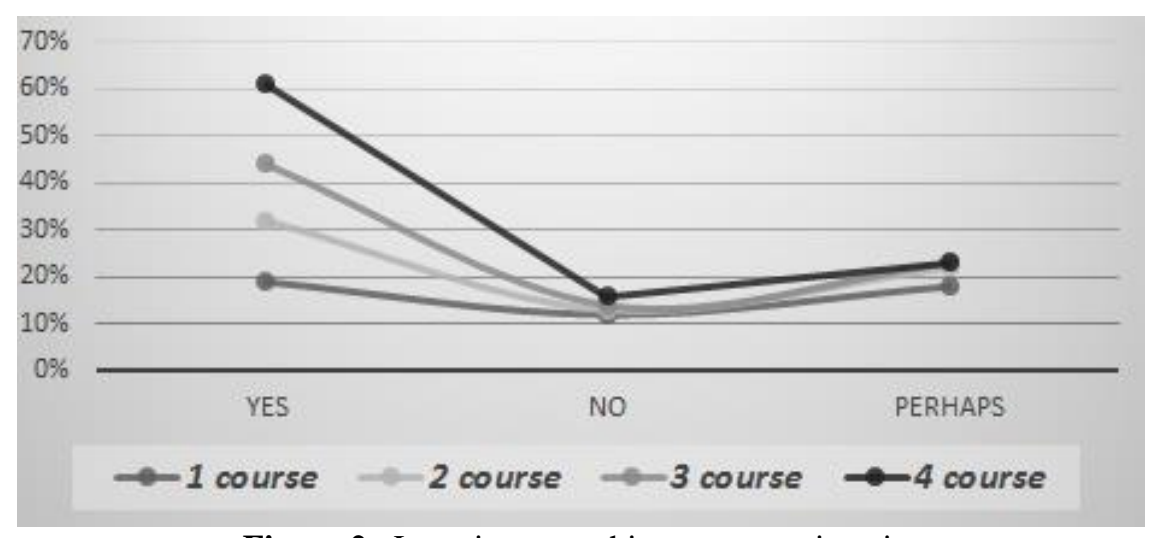

Figure 2. Learning something new at university

$61 \%$ of students who think that have directly benefit from their stay at the university, accept the university as a preparatory school for life. Of these, two thirds are after fresh-year students and one-third is fresh-year students. The same students give $12 \%$ of the answers "No", as part of $16 \%$ of all negative answers. $23 \%$ of the respondents are hesitant in their assessment, as here, the fresh-year students dominate again - $18 \%$ of all indicated the answer "Maybe". The conclusion is obvious that freshmen are hesitant in their assessments of their positive presence at the university, where they will acquire a medical degree. They do not even proceed from the fact that medical education would use them for personal assessments about their own health or that of their relatives and friends. However, $87 \%$ of all surveyed students definitely like "their" university and identify themselves with it.

Most of the students come to the university directly from the school desk and do not have the physical time to prepare themselves for life and responsibilities at the university. Their student behavior must be quickly replaced by the responsible, serious and active student behavior. The so-called "school manner" must be quickly replaced by self-initiative and the ambition to adapt quickly to the new conditions and requirements of academic occupation. In turn, this prepares young people for their more successful performance not only in science but also in life. ,The need of the individual for the training in HMU is a prerequisite for a high degree of efficiency of the learning-perceiving process....", as $\mathrm{N}$. Ivanova claims (10). Qualities such as: selfdiscipline, observation, organization and many others are extremely useful for everyone to possess and would be extremely useful in future life and work.

As already mentioned the educational process is dynamic in nature and should be guided in parallel. This can happen when the basic qualities and characteristics of the learners are known. In this aspect, the teachers participating in the study were asked an openended question in the questionnaire: "Which two main obstacles related to the personality of the students affect the quality of the learning process, according to them?"

The teachers' answers were mainly structured as follows:

- 97\% report the lower general education of the new coming students as a main factor that directly affects the quality of the educational process;

- 59\% consider the increased selfassessment of students as an obstacle in education, which does not allow them to work adequately and affect quality;

The percentage is more than one hundred, as the respondents indicate both answers. 


\section{CONCLUSION}

The existing vacuum in the Bulgarian educational system undoubtedly affects the quality of medical education. The easily accessible admission to HMU allows young people with insufficient general education, unclear ideas about the profession, high selfassessment and insufficient psychological maturity to pass through its filter. On the other hand, the financial constraints and the incomplete teaching staff, which is aging and affected by the burn-out syndrome, predetermine the lowering of quality of medical education assessment. The reasons for the latter are multifaceted and diverse in the individual universities and would be the basis for a separate scientific study. In no case should the work and professionalism of the academic community in its aspiration and desire to conduct quality training be placed under the common denominator of the above.

At the same time, the rapid development of electronic, communication and multimedia technologies has a direct positive impact on the learning process at HMU. In sync with the previous sentence, A. Andonova defines medical services as "one of the fastest growing sector, where the latest and high-tech scientific achievements are applied." (11). The skills of young people to use them actively are in their favor. The training is facilitated and illustrated and its quality is increased. The same author states that "the positive attitude of students to the learning process and respectively to their learning load is crucial for achieving learning outcomes, mastering and applying professional knowledge and skills in practice." (12).

Quality is a difficult component to assess in general, but when it must be done for the needs of medical education, the task becomes even more complicated.

The dynamically organized modern academic environment allows students with medical specialties to be active participants and moderators of their own education. Their active position and pretentiousness, based on good awareness, mastery of electronic technologies, high self-assessment and youth criticism define students as a major factor influencing the quality of educational goals at HMU.

\section{REFERENCES}

1. Velchev, Iv., Quality of education: national realities and global project, Electronic magazine, LiterNet № 6, 2005

2. Atanasova, Z., Sv. Dimitrova, Students majoring in Midwifery for elective training, contributing to the formation of their communicative competence, Health Care Magazine, Issue 3, pp. 8-14, 2014

3. Nikolova, M., "Competent care for the elderly", Scientific conference with international participation "Aging, health, geriatric care", pp.361-364, 2017

4. Miteva, Kr., The competence approach in the training of health specialists, XXIX scientific and technological session CONTACT 2012, Sofia, pp. 167-170, 2012

5. Mihova, M., Educational Policy of the EU, Problems and Priorities, ed. ASTARTA, Plovdiv, 2014,

6. https://eur-lex.europa.eu/legalcontent/BG/TXT/HTML/?uri=CELEX:320 07G1212(01)\&from=ES

7. https://op.europa.eu/en/publication-detail//publication/d27d3783-77f1-4f93-a38b-

41a6cae13e9f/language-bg/formatPDF/source-118486685

8. http://uni-sz.bg/wpcontent/uploads/truni/file/bolonski\%20proc es(2).pdf

9. https://zdravennavigator.bg/zdravnigrizi/26752-2020-svetovna-godina-nameditsinskata-sestra-i-akusherkata

10.Ivanova, N., Developing the professional clinical reasoning of students in the field of healthcare and public health, Dissertation, volume 1, Stara Zagora, 2016

11.Andonova, A. Key competence - warranty for successful realization on the labor market.Management \& Education / Upravlenie i Obrazovanie, Vol. 10 Issue 5, p10-14, 2014

12.Andonova, A., Students for course workload, Management \& Education / Upravlenie i Obrazovanie, Vol. 2 Issue 8, 2012 